\title{
Histórias de vida e experiências docentes no estágio supervisionado de licenciandos em Educação Física - modalidade EAD
}

\author{
André Marsiglia Quaranta* \\ Giovani De Lorenzi Pires**
}

\begin{abstract}
Resumo: A partir de estudo de múltiplos casos, objetivamos investigar aspecto específico da formação de professores de Educação Física na modalidade a distância (EAD), que se refere ao estudo das histórias de vida na/com a Educação Física no ensino básico e as experiências docentes no primeiro estágio supervisionado de quatro acadêmicos do polo de apoio presencial de Piritiba/BA, do curso de licenciatura oferecido pela Universidade de Brasília/Universidade Aberta do Brasil. Compreendendo que na modalidade EAD a relação com o conhecimento se dá majoritariamente mediada pelas tecnologias digitais, interessou refletir como se deu e foi interpretada essa inserção inicial dos estagiários, como professores em formação, no âmbito da cultura escolar, num campo cuja especificidade são as práticas corporais. Podese perceber que as histórias de vida influenciam em boa medida na escolha das estratégias didáticas dos estagiários, assim como na forma como eles interpretam suas experiências docentes no estágio supervisionado.

Palavras-chave: Formação de Professores a Distância. Formação de Professores em Educação Física. Estágio Supervisionado. Cultura Escolar.
\end{abstract}

"Professor da Rede Pública de ensino do Estado de Sergipe (SEED/SE) desde 2006, Aracaju, SE, Brasil. E-mail: andrequaranta@gmail.com

"Professor associado do Departamento de Educação Física da Universidade Federal de Santa Catarina, Docente e orientador credenciado no PPGEF/UFSC, Florianópolis, SC, Brasil. E-mail: giovanipires@cds.ufsc.br 


\section{INTRODUÇÃO}

A formação de professores no Brasil, incluindo os de Educação Física, vem atravessando grandes transformações nos últimos anos. Como exemplo, podemos destacar a elaboração das novas Diretrizes Curriculares para a Formação de Professores da Educação Básica ${ }^{1}$ e a educação a distância (EAD) como modalidade educacional ${ }^{2}$ ofertada em cursos de licenciatura em instituições de ensino superior credenciadas para tanto.

Essas modificações tiveram como ponto de partida a reforma do sistema educacional brasileiro provocada pela Lei de Diretrizes e Bases da Educação Nacional (lei no 9.394/96) e seus desdobramentos, possibilitando a formação de professores com um novo perfil docente, orientado para uma visão indissociável entre teoria e prática; aproximando a universidade da escola (e vice-versa); tendo uma formação voltada para o desenvolvimento de competências docentes a serem desenvolvidas na prática pedagógica.

Partindo do alerta aos poderes públicos diante da falta de professores conforme a demanda na educação básica, de acordo com o estudo de Gatti e Barreto (2009), diversas políticas de ampliação do acesso à educação superior, mirando, sobretudo as licenciaturas, foram implementadas pelo governo federal, na tentativa de minimizar este déficit, como por exemplo: o Programa Universidade Para Todos $\left(\mathrm{PROUNI}^{3}\right.$ ) e o Programa de Apoio a Planos de Reestruturação e Expansão das Universidades Federais (REUNI).

Paralelamente a este cenário, o governo Lula agregou ao seu projeto para o ensino superior a criação da Universidade Aberta do

\footnotetext{
10 Parecer CNE/CP 09/2001 serviu de base para a elaboração das Resoluções CNE/CP 01 e 02/2002, que tratam das diretrizes para a formação de professores. A Resolução CNE/CES 07/ 2004 trata das diretrizes para os cursos de Educação Física.

${ }^{2} O$ Decreto 5.622/ 2005 instituiu a EAD como modalidade educacional, regulamentando o artigo 80 da LDBEN 9.394/96, podendo ser ofertada na educação básica (abrangendo também a educação de jovens e adultos, especial e profissional) e na educação superior (graduação, especialização, mestrado e doutorado).

${ }^{3}$ Instituído pelo Governo Federal em 2004 com o objetivo de oferecer bolsas de estudos (parciais ou integrais) para alunos de baixa renda em universidades privadas conveniadas.
} 
Brasil (UAB), através do Decreto n ${ }^{\circ} 5.800 / 2006$, ou seja, um marco regulatório para a ampliação do acesso ao ensino superior, incluindo as licenciaturas a distância, que têm crescido de maneira considerável nos últimos anos (GIOLO, 2008).

A necessidade de estreitamento entre a universidade e a escola, possibilitando um diálogo ampliado com a produção do conhecimento, uma aproximação junto às culturas escolares (VIÑAO FRAGO, 2007) desde o começo dos cursos de licenciatura e o aumento do tempo de estágio para um mínimo de quatrocentas horas são algumas das questões apontadas nas novas diretrizes curriculares para a formação de professores implementada nos últimos dez anos. Neste sentido, o estágio supervisionado se caracteriza como um espaço privilegiado para a formação docente. Essa importância se revela ainda maior nas licenciaturas em EAD, já que nestas as experiências docentes junto às culturas escolares, ao longo da formação inicial, tendem a ser mais escassas e fragmentadas do que em cursos presenciais de formação de professores.

Em nosso estudo (QUARANTA, 2011), focamos as reflexões de acadêmicos de um curso de licenciatura em Educação Física na modalidade EAD sobre sua imersão na cultura escolar através do espaço/tempo proporcionado pelo estágio supervisionado, visando compreender como interpretam suas experiências docentes. No presente texto, nosso objetivo específico visa destacar as suas histórias de vida (biografias) relacionadas à Educação Física como componente curricular na educação básica e as possíveis implicações destas em suas primeiras experiências docentes como estagiários.

Segundo Bueno (2002), o estudo com base nas histórias de vida possibilita compreender aspectos da formação das identidades profissionais e indicam influências, por exemplo, na escolha do curso que fazem. $\mathrm{O}$ autor enfatiza certa escassez de pesquisas voltadas para grupos de sujeitos que ainda não ingressaram na profissão docente, como, por exemplo, os alunos que fazem cursos de licenciatura nas mais diversas áreas do conhecimento e que muito provavelmente vão ingressar na carreira do magistério. A partir das 
biografias dos sujeitos, sugere-se que sejam observadas as narrativas da formação intelectual dos professores nas mais variadas fases de suas trajetórias, para a compreensão destes elementos nas pesquisas educacionais.

Podemos inferir que o curso de licenciatura é um espaço de ressignificação das suas trajetórias construídas ao longo da educação básica em contato direto com os conhecimentos pertinentes ao campo acadêmico em que estão situados (Educação Física). Esta reconfiguração é experimentada em vários momentos do curso, mas, sobretudo a partir do exercício docente no estágio supervisionado, que tem grande importância na formação inicial do tornar-se professor. Se, por um lado, as histórias de vida são importantes para que os sujeitos possam reelaborar os significados da prática docente, por outro, estes também serão importantes para planejar, desenvolver e avaliar as experiências no decorrer do curso.

Essas considerações se fazem necessárias para uma leitura biográfica dos sujeitos desta pesquisa que, conforme Bueno (2002), para uma reflexão do "olhar sobre as experiências" como um importante alicerce na construção do "ser professor" nos cursos de formação inicial de professores, neste caso os de Educação Física a partir da modalidade EAD.

\section{Percursos metodológicos}

Das instituições que atualmente fazem parte do sistema UAB, a Universidade de Brasília (UnB) se destaca pelo pioneirismo na formação de professores de Educação Física na modalidade EAD, com o funcionamento de sete polos de apoio presencial espalhados em quatro regiões do país ${ }^{4}$, o que justifica a escolha dessa instituição como campo de pesquisa. Partindo do objetivo geral proposto da pesquisa, tomamos o contexto do estágio supervisionado como locus

\footnotetext{
${ }^{4}$ Os Polos de Apoio Presenciais estão localizados nas seguintes cidades: Porto Nacional (TO); Barretos (SP); Coromandel (MG); Alto Paraíso (GO); Piritiba (BA); Santana do Ipanema (AL); e Duas Estradas (PB).
} 
de observação e análise, e, neste sentido, optamos pelo polo da cidade de Piritiba/BA, por conta de os acadêmicos estarem iniciando as suas primeiras experiências docentes no estágio.

Caracterizamos assim a pesquisa como um estudo de múltiplos

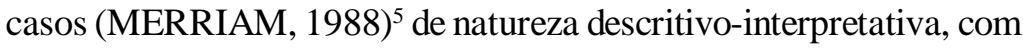
a observação de acadêmicos do curso que realizaram a primeira etapa do estágio supervisionado no primeiro semestre de $2010^{6}$.

Como critério de inclusão na pesquisa, optamos por acadêmicos que nunca haviam tido experiências docentes no âmbito da Educação Física. Dos trinta e seis alunos matriculados no estágio supervisionado, dez enquadravam-se neste perfil; destes, quatro participaram do estudo constituindo-se assim nos casos-sujeitos do estudo. Inicialmente, a descrição de cada caso foi organizada longitudinal e separadamente, destacando: i) aspectos das suas histórias de vida (explorando suas experiências anteriores com a Educação Física como alunos na educação básica), ii) a relação dos acadêmicos a partir do acesso ao curso e iii) as atividades realizadas no estágio e as suas práticas pedagógicas nas escolas em que estiveram inseridos. Além disso, empreendemos uma análise transversal sobre os casos, visando compreender como esses acadêmicos interpretam o papel do estágio supervisionado na sua formação, incluindo possíveis relações com as suas histórias de vida. Os processos interpretativos consideraram fundamentalmente as entrevistas concedidas pelos sujeitos-casos, objetivando agrupar as características mais específicas e recorrentes entre eles na forma de eixos de discussão, conforme a proposta de análise temática (MINAYO, 2006), como uma variação discursiva menos rígida do que a constituição de categorias da análise de conteúdo sugerida por Bardin (2009). Da aplicação das técnicas da análise temática sobre o conteúdo das entrevistas dos sujeitoscaso resultaram três eixos principais: i) a memória das suas aulas de Educação Física na educação básica; ii) o relato das situações-

${ }^{5}$ Citado por Bogdan e Biklen (1994, p. 89).

${ }^{6} \mathrm{O}$ estudo foi aprovado pelo Comitê de Ética de Pesquisa com Seres Humanos da UFSC. Parecer Consubstanciado ํㅜ 773/10. 
problema vivenciadas no estágio e as alternativas buscadas; iii) as questões objetivas/operacionais relativas à supervisão do estágio ${ }^{7}$.

\section{STTUANDO O CAMPO DE INVESTIGAÇÃO E O ESTÁGIO SUPERVISIONADO}

O curso de formação de professores de Educação Física a distância é ofertado pela UnB, em parceria com a UAB, com carga horária total de 2.910 horas e duração de oito períodos, ofertados semestralmente $^{8}$. O polo funciona em instalação cedida pelo Governo do Estado da Bahia à Prefeitura Municipal de Piritiba, no centro da cidade, contando com seis funcionários cedidos pela prefeitura para serviços de secretariado, biblioteca, serviços gerais e portaria.

Inseridos na estrutura curricular do curso no eixo Conhecimentos Didáticos Pedagógicos, os Estágios Supervisionados são realizados em quatro semestres, a partir da segunda metade do curso. Dessa forma o primeiro estágio, que foi acompanhado na pesquisa, ocorre na educação infantil e, sucessivamente, em mais três etapas: primeiro e segundo ciclo do ensino fundamental; e no ensino médio.

Segundo relato do coordenador do polo, para a organização do estágio foi feito um levantamento das escolas públicas e privadas existentes no município, que acolheriam estagiários. Posteriormente, os alunos escolheram livremente, entre as escolas disponíveis, aquela em que fariam suas intervenções pedagógicas junto à educação infantil. A oficialização do estágio dava-se por uma carta de apresentação do curso e da autorização por parte da direção das escolas. Na carta era explicada aos diretores das escolas a finalidade do estágio, descrevendo o desenvolvimento desta em duas etapas (observação e intervenção).

Também foi repassado aos acadêmicos um Formulário de Acompanhamento de Estágio na Instituição, que consistia no

\footnotetext{
${ }^{7}$ No presente texto, a discussão desse eixo não será apresentada, ainda que as suas consequências repercutam, de forma subliminar, nos outros dois eixos temáticos.

${ }^{8}$ Dados do período em que a pesquisa foi realizada.
}

Movimento, Porto Alegre, v. 19, n. 02, p. 185-205, abr/jun de 2013. 
preenchimento das datas, horários e atividades realizadas por eles, devendo exercer ao menos quatro horas semanais de docência, autenticadas pelo professor regente de classe.

Segundo o tutor presencial do polo, os tutores foram capacitados pela $\mathrm{UAB} / \mathrm{UnB}$ para as atividades a serem desenvolvidas durante $\mathrm{o}$ período letivo, sendo que a participação destes seria a de fazer o levantamento das escolas e auxiliar aos acadêmicos no preenchimento dos documentos necessários. O acompanhamento pedagógico do estágio, como planos de ensino e planos de aula, seria feito via plataforma, pelo tutor à distância e pelo professor da disciplina.

\section{Os casos ESTUDADOS}

No semestre observado, todos os sujeitos-caso, além do estágio supervisionado na educação infantil, cursavam as disciplinas: Políticas e Fundamentos da Educação Básica, Crescimento e Desenvolvimento Motor, Pedagogia dos Esportes Coletivos e Pedagogia da Educação Física na Educação Infantil. Com média de idade de vinte e seis anos, Iza, Max, Carla e Andréa ${ }^{9}$ possuem uma característica em comum: tem uma ocupação profissional fora do âmbito da Educação Física. A seguir, descrevemos características individuais dos sujeitoscasos:

Iza trabalha como secretária em uma escola da rede pública municipal em Piritiba/BA e decidiu fazer o seu estágio numa instituição diferente da que trabalhava, por entender que, na sua escola, os alunos não iriam vê-la como professora e sim como secretária e também por não achar adequado o espaço físico da escola para a prática de aulas de Educação Física.

Ela relatou que teve Educação Física a partir da $5^{\mathrm{a}}$ série do ensino fundamental e até o $1^{\circ}$ ano do ensino médio; nos dois últimos anos de escola ela passou a estudar à noite e a disciplina não era

${ }^{9}$ Nomes fictícios.

Movimento, Porto Alegre, v. 19, n. 02, p. 185-205, abr/jun de 2013. 
ofertada - muito provavelmente devido à interpretação dada ao artigo $26^{\circ}$ da LDBEN no 9.394/96, que até $2003^{10}$ em sua redação apresentava como facultativa no período noturno.

Max, técnico de informática, escolheu estagiar na escola privada em que havia estudado quando criança e adolescente. Ele atesta que foi muito tranquilo, pelo fato dele conhecer a maioria dos agentes escolares. Em outra situação, ele prestou serviços profissionais em sua área de competência à mesma escola.

Tendo estudado durante a educação básica na rede privada de ensino, as aulas de Educação Física com professores habilitados somente se deram a partir da segunda metade do ensino fundamental. As aulas eram organizadas a partir da iniciação dos fundamentos básicos de algumas modalidades esportivas, como por exemplo: futebol, natação e voleibol.

Karla, desde antes de ingressar no curso, faz trabalho voluntariado com menores carentes junto à igreja evangélica da qual faz parte. Para ela, a maior dificuldade estava no que fazer na Educação Física com crianças tão pequenas.

Durante a sua passagem como estudante na educação básica, a recordação de Karla sobre as aulas era, predominantemente, brincadeiras como o "baleado" (queimado) e cantigas de roda feita pela professora regente, da $1^{\mathrm{a}}$ a $4^{\mathrm{a}}$ série. Da $5^{\mathrm{a}}$ série do ensino fundamental até o $3^{\circ}$ ano do ensino médio as atividades recreativas se destacavam.

Andrea, que trabalha como auxiliar de exames laboratoriais, foi a estagiária que mais apresentou dificuldades na sua experiência docente, pelo fato de não conseguir dominar a turma; parece ter sido a que mais sentiu a falta de uma supervisão mais próxima que, segundo ela, poderia ter sido importante para sanar algumas das suas dificuldades.

A sua primeira aula de Educação Física somente aconteceu a partir da $5^{\mathrm{a}}$ série na escola em que estudava e se baseavam em

A redação foi alterada pela última vez através da Lei nํ⒑793/2003.

Movimento, Porto Alegre, v. 19, n. 02, p. 185-205, abr/jun de 2013. 
exercícios ginásticos, dos quais relatou gostar. A partir da $7^{\mathrm{a}}$ série, ela lembra que as aulas eram divididas em aulas "teóricas" e "práticas", mas ela não guarda boas lembranças desse período.

Após esta breve apresentação dos sujeitos que estiveram envolvidos neste estudo, buscamos agrupar as características mais específicas sobre as suas experiências docentes no estágio supervisionado com o intuito de estabelecer uma discussão transversal entre os casos a partir das suas histórias de vida.

\subsection{As HistóRIAS de VidA NA CONSTRUÇÃO dA EXPERIÊNCIA DOCENTE}

Para destacar a relação das histórias de vida na construção da experiência docente - em nosso caso, a partir das práticas pedagógicas materializadas na primeira etapa do estágio supervisionado de Iza, Max, Karla e Andrea - fizemos as análises dos depoimentos, como já destacado na descrição dos procedimentos metodológicos, sob dois eixos: i) os relatos sobre a organização pedagógica dos seus professores de Educação Física na educação básica; ii) pistas sobre a atuação docente destes acadêmicos no estágio, levando em consideração tanto as situações que fazem alusão às suas histórias de vida, como das situações assimiladas durante a formação docente.

Das questões esboçadas em suas histórias de vida na educação básica, na disciplina Educação Física, as práticas corporais mais evidenciadas foram os jogos pré-desportivos, como, por exemplo, o "queimado" (ou "baleado" conforme algumas descrições relatadas) e os esportes propriamente ditos. Dentre as modalidades esportivas praticadas, o futebol foi hegemônico, seguidos do voleibol e do basquetebol. Somente no caso de Max, práticas como a natação e o tênis de mesa estiveram presentes, lembrando que sua escolarização se deu em colégio privado. No caso de Andrea, atividades ginásticas estavam presentes nas aulas de Educação Física apenas durante a sua passagem pela $5^{\mathrm{a}}$ série do ensino fundamental.

A partir dos relatos sobre a percepção que os sujeitos tinham das aulas de Educação Física na educação básica, predominantemente, foi lembrado que os próprios alunos se 
organizavam para realizar as atividades que a maioria, ou pelo menos num consenso mínimo, estava interessada em praticar, de forma recreativa, conforme pode ser destacado na fala a seguir:

os professores deixavam os materiais a vontade para o que gente bem quisesse fazer durante a aula... A aula era por volta de 50 minutos e aí tínhamos duas aulas seguidas, e se não estou enganada eram nas sextas-feiras, nas duas últimas aulas. Daíos meninos pegavam a bola... Chamavam as meninas para completar a turma e eles incentivavam as meninas a jogarem o vôlei (IZA - ENTREVISTA).

Diante deste dado podemos refletir a Educação Física, como uma prática social que ocorre no espaço escolar (BRACHT, 1999), a partir das transformações geradas pela LDBEN n ${ }^{\circ}$ 9.394/96, que a torna componente curricular obrigatório, integrado ao projeto pedagógico da escola. Fruto das discussões geradas no campo acadêmico desde a década de 1980, entender a Educação Física como um componente curricular não apenas equaliza o seu status em relação às demais disciplinas escolares, mas implica que seja tratada como um conhecimento específico e organizado sequencialmente em cada série na educação básica. Em vista do que foi percebido neste estudo, as mudanças na prática pedagógica decorrente desse novo status da educação física escolar é um processo ainda em desenvolvimento que precisa ser debatido no âmbito da formação docente inicial e continuada.

A partir das sensações que os sujeitos tinham ao lembrarem-se das aulas de Educação Física podemos destacar em pares, aspectos positivos e negativos ${ }^{11}$. Ao ser indagado sobre o que mais havia marcado em suas aulas na educação básica, sob o ponto de vista positivo, Max relembrou com certo saudosismo das suas medalhas conquistadas durante os jogos escolares, o que parece confirmar a tese de Kunz (1994) de que vivências de sucesso no esporte na

\footnotetext{
${ }^{11}$ Abordamos aqui estes aspectos de forma que essas sensações foram construídas sob o ponto de vista da experiência com a cultura de movimento. Se as experiências foram boas para os sujeitos, as consideramos como positivas; e, se as experiências não foram agradáveis para eles, identificamos como negativas.
} 
escola produzem atitudes positivas em relação à Educação Física e que seu inverso também parece ser verdadeiro, isto é, experiências de fracasso também marcam indelevelmente sua história de vida na área:

O que marcou foi essa questão das olimpíadas, que tive o privilégio de ser primeiro lugar em algumas provas. Ganhei três provas de natação; duas de tênis de mesa; revezamento em equipe. As medalhas estão lá guardadas. Até já ganhei dois torneios de futebol por classe. Agora, sobre o cotidiano nas aulas, não me lembro de muita coisa marcante. (MAX - ENTREVISTA).

Karla também relembra com alegria e se identifica como ativa nas aulas educação básica, o que pode ser observado no recorte seguinte:

Eu sempre me considerei muito ativa. Então, quando eu pensava em fazer aulas de Educação Física eu já me animava bastante. Na verdade, eu e alguns colegas, na hora do recreio, costumávamos jogar basquete. Eu não sabia nada de basquete, mas eu gostava muito. Lembro que ficávamos muito na quadra, tentando marcar cestas. São os momentos que mais recordo. (KARLA - ENTREVISTA).

Iza revela certa ambiguidade em relação à Educação Física na escola, apontando aspectos positivos e negativos: quando relembra das aulas, ela recorda com felicidade os momentos divididos com seus colegas e amigos; porém, em alguns momentos relembra o medo de se machucar:

Eu gostava do vôlei, embora não fosse tão habilidosa, mas gostava. Até porque eu sou medrosa. O futebol era bom, porém eu tinha medo que a bola batesse no meu rosto. Também tinha medo de dar uma bolada na janela ou a possibilidade de machucar alguém. Participava, mas tinha medo dessas coisas. (IZA - ENTREVISTA).

Andrea demonstrou não ter boas recordações das suas aulas, porque se sentia decepcionada pela não continuidade das aulas de 
ginástica, das quais gostava, e pelo fato de se sentir cobrada constantemente em "jogar certo" nas aulas predominantes do conteúdo esporte, desenvolvidas posteriormente, tornando a aula de Educação Física desestimulante, como se percebe pelo depoimento a seguir:

O período que mais marcou a minha vida nas aulas foi durante a $5^{\mathrm{a}}$ série, por conta das aulas de ginástica. Nos anos seguintes eu odiei. O professor chegava, dava uma bola e ficava lá sentado. Então, toda aula de Educação Física eu inventava uma cólica, porque eu não queria participar. (ANDREA - ENTREVISTA).

Para a maioria dos sujeitos, as aulas eram vistas como "livres", com exceção de Karla, que apontou que tinha aulas teóricas - com aulas expositivas sobre as regras de cada modalidade esportiva - e aulas práticas - com a experimentação destas modalidades nas aulas realizadas fora da sala de aula.

A construção da identidade profissional dos professores em formação tem ligação com as suas histórias de vida. Em pesquisa desenvolvida por Figueiredo (2004) com alunos de graduação em Educação Física é destacado que as suas experiências anteriores incidem significativamente no processo de construção e reconstrução de identidades, já que a constituição destas assume um caráter provisório e que vai sendo modificada ao longo da experiência docente.

A autora entende que a proximidade com as culturas escolares pode ser determinante na formação docente, inclusive, por exemplo, nas práticas corporais escolhidas pelo professor para a elaboração da sua prática pedagógica:

Vistas dessa forma, as experiências sociocorporais ocupam lugar importante, mas, por vezes 'perverso' nos processos de formação inicial, com influência nos currículos de formação; na prática pedagógica cotidiana, com influência no ensino de conteúdos; e na formação e transformação de identidades, com influência no tornar-se professor. (FIGUEIREDO, 2009, p. 4). 
Reforça essa tese o fato de que dos nossos sujeitos-caso, Max foi o único a apontar que não pretende exercer a função de professor, pelo fato do curso ser de licenciatura e de não ter uma formação voltada para o treinamento esportivo, como era seu desejo:

\begin{abstract}
Logo que começou a parte da fisiologia eu fiquei empolgado. Quando o curso se voltou mais para a questão pedagógica acabei ficando frustrado. Não me sinto a vontade em dar aulas na escola. Estar em sala de aula como professor é interessante por estar contribuindo na formação do cidadão, construindo conhecimento, mas não me sinto apto, não me vejo como professor em sala de aula. Vou concluir o curso, mas não pretendo atuar na sala de aula. Prefiro algo voltado para o rendimento esportivo. (MAX ENTREVISTA).
\end{abstract}

Vale recordar que ele foi o único a relatar em sua biografia um vínculo mais estreito com o esporte na educação básica. Como a sua história de vida apontou diversas situações de sucesso em torneios e competições, a opção em atuar profissionalmente com o esporte de rendimento parece ter sido influenciada pelas suas experiências anteriores.

Além do envolvimento com as experiências anteriores de acadêmicos que, no ingresso em cursos de licenciatura, as ressignificam (em tese) para o "tornar-se professor", deve-se também levar em consideração pontos a serem discutidos na formação profissional em Educação Física, sintetizada por Betti e Mizukami (1997) a partir de estudo realizado com o método de histórias de vida, que traz algumas sugestões a serem discutidas por alunos e professores, incentivando inclusive pesquisas com o intuito de observar estas narrativas para poderem melhor compreender o processo de formação de professores.

Podemos destacar, diante das experiências no estágio, algumas interpretações possíveis a partir do planejamento organizado pelos acadêmicos e a sua materialização nas intervenções. Sem negar a importância das histórias de vida destes acadêmicos, é preciso reconhecer que outros elementos do cotidiano da formação, 
sobretudo as disciplinas desenvolvidas, também contribuem para as escolhas do fazer pedagógico. No entanto, o que se percebe é que, associados às lembranças das suas biografias, esses saberes docentes terminam por produzir um mosaico eclético e pouco organizado de práticas do ensino da Educação Física na educação infantil.

Exemplo disso decorre da observação de alguns aspectos do estágio dos sujeitos-caso. Durante o semestre em que ocorreu o estágio, as disciplinas Crescimento e Desenvolvimento Motor e Pedagogia da Educação Física Infantil também foram cursadas pelos nossos sujeitos-casos. Em seus planejamentos do estágio pudemos observar que houve uma influência na construção dos discursos objetivados a partir da psicomotricidade. Porém, ao mesmo tempo traziam elementos como desenvolvimento da ludicidade e a socialização dos alunos através dos jogos e brincadeiras, o que denota características subjetivas que vem sendo mais discutidas com base nas ciências sociais e humanas. Vejamos, por exemplo, a organização das unidades temáticas desenvolvidas por Iza:

- Desenvolvimento da psicomotricidade, estimular o desenvolvimento das habilidades motoras básicas, vivências corporais, ludicidade, recreação, afetividade, companheirismo, socialização $\left(1^{\mathrm{a}}\right.$ e $2^{\mathrm{a}}$ semana);

- Estimular o desenvolvimento as vivências corporais, ludicidade, recreação, afetividade, socialização por meio de improvisações e interpretações musicais $\left(3^{\mathrm{a}}, 4^{\mathrm{a}}\right.$ e $5^{\mathrm{a}}$ semana);

- Coordenação motora; respeito; trabalho em grupo; noções de higiene; socialização e afetividade $\left(6^{\mathrm{a}}\right.$ semana);

- Socialização; afetividade; respeito pelo próximo; trabalho em grupo; coordenação motora; e noções de higiene ( $7^{\mathrm{a}}$ e $8^{\mathrm{a}}$ semana). 
No interior do estágio, a transposição didática é um elemento central no exercício docente, pois implica a ressignificação dos conhecimentos durante o curso de formação em conteúdos escolarizados numa linguagem adaptada para o seu desenvolvimento na escola. Nesses momentos os acadêmicos (futuros professores) iniciam o exercício docente. O relato feito por Karla mostra como ela procurava organizar suas intervenções:

[...] utilizávamos brincadeiras que pudessem estar relacionadas com a coordenação motora. Com as habilidades básicas da criança, como correr, saltar e pular, por exemplo. Buscávamos brincadeiras para trabalhar essas habilidades, visando também o desenvolvimento das questões afetivas e sociais também. (KARLA - ENTREVISTA).

Concluindo essas reflexões, podemos destacar uma questão curricular relacionada à realidade do componente curricular na escola e que, de certa forma, acabou gerando uma problemática conjuntural no estágio dos casos estudados. A inserção de uma etapa do estágio a ser realizada na educação infantil pode ser considerada como um grande avanço na formação de professores de Educação Física. Porém, como a atuação destes professores é uma prática pedagógica ainda muito pouco difundida nas escolas do país inteiro, isso denota uma dificuldade que acabou tendo que ser enfrentada pelos estagiários; estamos no referindo à falta de supervisão específica do estágio no âmbito escolar, já que os professores das turmas em que os estagiários atuaram (em tese, seus supervisores diretos) eram pedagogos, portanto sem formação em Educação Física. Além disso, a falta de supervisão direta (nas escolas) por parte do polo e da instituição que oferece o curso gerou uma dificuldade conjuntural que se somou a anteriormente referida. Assim, quando as dificuldades surgiam, os estagiários contavam apenas com suas memórias da Educação Física escolar e/ou com o compartilhamento das estratégias adotadas por outros colegas para resolverem seus próprios problemas. 


\section{CoNSIDERAÇõEs FINAIS}

A formação profissional de atuação no magistério exige a compreensão de que esta se configura como um complexo multifacetado, em que tanto as suas histórias de vida, como suas experiências preliminares durante o curso de licenciatura são aspectos importantes, que vão se somar àquelas decorrentes da sua inserção mais sistemática à cultura escolar, através do estágio supervisionado. Ao adentrarem efetivamente nas escolas por um período mais prolongado, as rotinas cotidianas de tomada de decisões, elaboração de planejamentos, transposição didática do conhecimento, avaliação dos processos, etc., são elementos que vão sedimentar a prática pedagógica destes futuros professores. Vale ressaltar a necessidade de ampliar o debate sobre os estudos que tratam do tempo e do espaço escolar na formação no campo acadêmico da Educação Física.

Apesar das limitações que observamos com relação às condições de execução e de supervisão do estágio supervisionado, os depoimentos dados por três dos quatro sujeitos-casos, que desejam se tornar professores de Educação Física escolar, indicam que as experiências docentes vividas por eles no estágio deixaram legados positivos, vindo a se constituir em um elemento significativo em sua formação acadêmica. Dessa forma, reiteramos a importância da criação de mecanismos de supervisão e acompanhamento mais próximo da cultura escolar por parte da instituição formadora e do seu polo presencial.

Embora marcado pela especificidade da modalidade de ensino na qual foi realizada a pesquisa (EAD), nossa postura investigativa transitou na tensão entre a educação presencial e a distância, sem pré-julgamentos, balizada, sobretudo, na questão da qualidade da formação de professores de Educação Física, independente da modalidade em que ela estiver ocorrendo. Neste sentido, as experiências docentes configuradas no estágio supervisionado podem dizer muito sobre o curso. Portanto, se faz necessário observar melhor como ocorre esta formação, investigando o cotidiano dos acadêmicos. 
Foi o que pretendemos fazer ao destacar e compreender a formação do professor na modalidade a distância em suas primeiras experiências docentes na escola. Considerando inclusive que a possível ausência de vivências preliminares com a docência na área pode ser remediada pela rememoração das suas histórias de vida com o componente curricular na educação básica para a construção de suas experiências no estágio supervisionado. 


Life stories and teaching experiences in the
supervised internship of undergraduate
students of physical education - distance
education mode (EAD)
Abstract: From multiple case study, we aimed to
investigate specific aspects of training of physical
education teachers in distance learning, which refers
to the study of life stories in and with Physical
Education in elementary education and teaching
experiences in the first supervised internship of four
academics from Piritiba / BA, of a course offered by
the University of Brasilia / Brazil Open University.
Realizing that, in the Distance Teacher Education mode
the relation to the knowledge occurs mainly mediated
by digital technologies, it was relevant to reflect how
this initial insertion of interns was interpreted by them
while training within the school culture. One can notice
that life stories largely influence the choice of teaching
strategies for internships, as well as in how they
interpret their experiences in the supervised internship.
Keywords: Distance Teacher Education. Physical
Education Training. Supervised Internship. School
Culture.




Las historias de vida y experiencias de
enseñanza en la práctica supervisada de los
académicos de educación física - modalidad a
distancia (EAD).
Resumen: A partir de estudio de múltiples casos,
objetivamos investigar el aspecto específico de la
formación de profesores de Educación Física en la
modalidad a distancia (EAD), que se refiere al estudio
de las historias de vida en la/con la Educación Física
en la enseñanza básica y las experiencias docentes
en la primera práctica supervisada de cuatro
académicos del polo presencial de Piritiba/BA, del curso
de licenciatura ofrecido por la Universidade de Brasília/
Universidade Aberta do Brasil. Comprendiendo que
en la modalidad EAD la relación con el conocimiento
ocurre en su mayoría mediada por las tecnologías
digitales, interesó reflexionar cómo se dio y fue
interpretada esta inserción inicial de los estudiantes-
practicantes como profesores en formación, en el
ámbito de la cultura escolar, en un campo cuya
especificidad son las prácticas corporales. Se puede
percibir que las historias de vida influencian en buena
medida en la elección de las estrategias didácticas de
los estudiantes-practicantes, así como en la forma
como ellos interpretan sus experiencias docentes en
la práctica supervisada.
Palabras-clave: Formación de Profesores a Distancia.
Formación de Profesores en Educación Física.
Práctica Supervisada. Cultura Escolar.

\section{REFERÊNCIAS}

BARDIN, L. Análise de conteúdo, 2 ed. rev. e ampl. Lisboa: Edições 70, 2009.

BETTI, I. C. R; MIZUKAMI, M. da G. N. História de vida: trajetória de uma professora de educação física. Motriz, Rio Claro, v. 3, n. 2, dez. 1997.

BOGDAN, R. C.; BIKLEN, S. K. Investigação qualitativa em educação: uma introdução à teoria e aos métodos. Porto: [s.n.], 1994.

BUENO, B. O. O método autobiográfico e os estudos em histórias de vida de professores: a questão da subjetividade. Educação e pesquisa, São Paulo, v. 28, n. 1, p. 11-30, jan./jun. 2010.

BRACHT, V. Educação Física e ciência: cenas de um casamento (in)feliz. ljuí: Unijuí, 1999. 
BRASIL. Decreto no 5.800. Criação da Universidade Aberta do Brasil. Brasília, 2006.

1996.

Lei no 9.394. Lei de diretrizes e bases da educação nacional. Brasília,

BRASIL. Conselho Nacional de Educação. Resolução CNE/CP nำ 02, de 27 de agosto de 2004.

Resolução CNE/CP no 01, de 18 de fevereiro de 2002.

Resolução CNE/CP nº 02, de 19 de fevereiro de 2002.

Parecer CNE/CP no 09, de 08 de maio de 2001.

BRASIL. Ministério da Educação. Instituto Nacional de Estudos e Pesquisas Educacionais. Censo da educação superior. Brasília, 2008.

Censo de Profissionais do Magistério. Brasília, 2003.

BRASIL. Ministério da Educação. Secretaria de Educação a Distância. Referenciais de qualidade para cursos a distância. Brasília, 2003.

Brasília, 2007.

Referenciais de qualidade para educação superior a distância.

FIGUEIREDO, Z. C. C. Uma experiência de formação de professores de educação física na perspectiva do formar-se professor. Pensar a Prática, Goiânia, n. 12/ 33, p. 1-11, set./dez. 2009.

. Formação docente em educação física: experiências sociais e relação com o saber. Movimento, Porto Alegre, n. 10, p. 89-111, 2004.

GATTI, B. A.; BARRETO, E. S. de S. Professores do Brasil: impasses e desafios. Brasília: UNESCO, 2009.

GIOLO, J. A educação a distância e a formação de professores. Educação e Sociedade, Campinas, v. 29, n. 105, p. 1211-1234, set./dez. 2008.

KUNZ, E. Transformação didática do esporte. ljuí: Unijuí, 1994.

MERRIAM, S. Case study research in education: a qualitative approach. San Francisco, CA: Jossey-Bass, 1988.

MINAYO, M. C. S. O desafio do conhecimento: pesquisa qualitativa em saúde. 9. ed. rev. e apr. São Paulo: Hucitec, 2006.

MOLINA, R. M. K. O enfoque teórico metodológico qualitativo e o estudo de caso: uma reflexão introdutória. In: TRIVIÑOS, A. N. S.; MOLINA NETO, V. A pesquisa qualitativa em educação física: alternativas metodológicas. Porto Alegre: Editora da UFRGS, 1999. p. 95-105. 
UNIVERSIDADE DE BRASÍLIA. Projeto Político Pedagógico: Curso de licenciatura em educação física UAB-UnB. Brasília, 2009.

QUARANTA, A. M. Formação de professores de educação física na modalidade de educação à distância: experiências docentes no estágio supervisionado. Dissertação (Mestrado em Educação Física) - Programa de PósGraduação em Educação Física, Universidade Federal de Santa Catarina, Florianópolis, 2011.

VIÑAO FRAGO, A. Sistemas educativos, culturas escolares e reformas. Lisboa: Edições Pedago, 2007.

Endereço para correspondência:

Avenida Gonçalo Rolemberg Leite, № 1960,

Alphaville 1, bloco Delta, ap. 402.

Aracaju, Sergipe.

CEP: 49050-370

Recebido em: 03.10.2011

Aprovado em: 24.02.2013 